\title{
Terapias aplicadas no tratamento das lesões por queimaduras de terceiro grau e extensão variável: revisão integrativa
}

\author{
Therapies applied in the treatment of injuries by burns of third degree \\ and variable extension: an integrative review
}

Andréia Vieira da Silva ${ }^{1}$ (D) , Denise de Sousa Tavares $^{1}$ (D) , Pedro Anderson Miranda Tavares $^{1}$ (D) , Carina Oliveira dos Santos ${ }^{2}$ (D)

\begin{abstract}
RESUMO
Lesões por queimaduras se apresentam como simples ou graves de acordo com sua profundidade, extensão e localização. Diversas terapias são lançadas no mercado, devendo prover um ambiente úmido, amplo aspecto antimicrobiano e serem efetivas, mesmo na presença de grande quantidade de exsudato, visando os benefícios que trarão para o processo de cicatrização. Neste sentido, este estudo objetivou revisar a literatura acerca da caracterização clínica e terapias aplicadas no tratamento das queimaduras de terceiro grau e de extensão variável. Para alcançar o objetivo proposto, foi realizada uma revisão integrativa da literatura nas bases de dados LILACS, BDENF e SciELO. Foram selecionados 17 artigos e os resultados apontaram que os curativos a base de prata são os mais utilizados, dentre eles, sulfadiazina de prata, prata nanocristalina e espuma absorvente. Para casos particulares mais complexos, a matriz de regeneração dérmica assume-se como uma alternativa eficaz e segura. A utilização da terapia por pressão negativa no tratamento da contratura cicatricial, muito presente nas lesões de terceiro grau, agrega como vantagem o fato de o paciente não precisar ficar imobilizado e imóvel após as cirurgias. Dentre as terapias inovadoras no tratamento de queimaduras, evidenciou-se o uso de enxerto da pele de tilápia, que foi citado por um estudo como um possível subproduto com alta aplicabilidade clínica. Ao longo do estudo foi possível concluir que os pacientes necessitam de uma assistência adequada desde os cuidados imediatos até o fim da reabilitação. Com o passar dos anos, inovações terapêuticas vêm sendo estudadas para serem implantadas no tratamento ao paciente queimado, entre elas a substituição de pele vem ganhando espaço pelos resultados positivos.
\end{abstract}

Palavras-Chaves: Curativos; Queimaduras; Terapias.

\begin{abstract}
Burn injuries are classified as simple or severe according to their depth, extent, and location. Several therapies are commercially available, which should provide a humid skin, broad antimicrobial aspect and be effective, even if a large amount of exudate is present, aiming at benefiting the healing process. Therefore, this study aimed to review the literature on the clinical characterization and therapies applied in the treatment of third-degree burns and of variable extension. To reach the proposed objective, an integrative literature review was carried out in the LILACS, BDENF, and SciELO databases. Seventeen papers were selected, and the results showed that silver-based dressings are the most used, and among these, stand out: silver sulfadiazine, nanocrystalline silver, and an absorbent foam. For more complex cases, the dermal regeneration matrix is an effective and safe alternative. The use of negative pressure therapy in the treatment of scar contracture, present in third-degree injuries, has some advantage since the patient does not need to be immobilized and still after the surgeries. Among the innovative therapies in the treatment of burns, the use of tilapia skin graft was evidenced, which was mentioned by a study as a possible by-product with high clinical applicability. Throughout the study, it was possible to conclude that patients need adequate assistance, from immediate care, until the end of the rehabilitation. Over the years, therapeutic innovations have been studied to be implemented in the treatment of burned patients, including the replacement of skin, which has been highlighted due to the positive results.
\end{abstract}

Keywords: Bandages; Burns; Therapeutics.

Enfermeiros, Pós-Graduação em Enfermagem em Estomaterapia da Escola Bahiana de Medicina e Saúde Pública, Salvador (BA), Brasil.

2 Fisioterapeuta, Doutora e Mestre em Modelagem Computacional (CIMATEC/BA). Docente Adjunta da Escola Bahiana de Medicina e Saúde Pública e da Universidade do Estado da Bahia.

$\triangle$ Denise de Sousa Tavares. Rua Silveira Martins, 3386, Cabula. CEP: 41150-000. Salvador (BA), Brasil.

denise.tavares@ebserh.gov.br | denise.ba@hotmail.com | Recebido em: 13/07/2020 | Aprovado em: 14/09/2020 


\section{INTRODUÇÃO}

As queimaduras são definidas pela Sociedade Brasileira de Queimaduras como feridas traumáticas causadas, na maioria das vezes, por agentes térmicos, químicos, elétricos ou radioativos ${ }^{1}$. Avalia-se que no Brasil acontecem em torno de 1.000.000 de incidentes por queimaduras ao ano, sendo que 100.000 pacientes buscarão atendimento hospitalar e, destes, cerca de 2.500 pacientes irão a óbito direta ou indiretamente em função de suas lesões².

Pode-se classificar as queimaduras quanto à profundidade sendo de primeiro, segundo ou terceiro grau. Na de $1^{\circ}$ grau ocorre um acometimento somente da epiderme; na de $2^{\circ}$ grau a lesão atinge epiderme e derme; na de $3^{\circ}$ grau a destruição tecidual pode atingir tecido subcutâneo, tendões, ligamentos, músculos e ossos ${ }^{3}$. Quanto à extensão, as queimaduras são identificadas de acordo com o percentual de área do corpo acometida, podendo o indivíduo ser classificado em: pequeno, médio e grande queimado. As queimaduras de terceiro grau demandam maiores cuidados, pois ocorre a destruição de todas As camadas da pele, tempo maior de hospitalização, risco de infecção, e tratamento mais complexo, exigindo cirurgia reparadora com enxertia de pele ${ }^{5}$.

Diversas terapias são lançadas no mercado, devendo prover um ambiente úmido, amplo aspecto antimicrobiano, ter baixa toxicidade, ação rápida, não provocar irritação e não promover aderências. Os serviços de referência devem instituir protocolos para que os profissionais de saúde entendam as principais abordagens no atendimento ao paciente queimado, visando os benefícios que trarão para o processo de cicatrização ${ }^{6}$. Neste cenário, a assistência de enfermagem atua do estágio clínico agudo até a fase de reabilitação e, para tanto, precisa ter conhecimento dos recursos disponíveis no mercado e estar constantemente capacitada, com intuito de reduzir complicações e taxa de mortalidade ${ }^{7}$.

Neste sentido, é importante conhecer as terapias aplicadas no tratamento das lesões por queimaduras, visando escolher a terapêutica adequada para cada caso, minimizando as sequelas e óbitos relacionados a este tipo de lesão. Diante do exposto, o objetivo do estudo foi caracterizar, por meio de revisão integrativa da literatura, as queimaduras de terceiro grau e de extensão variável e identificar as terapias aplicadas no tratamento destas lesões.

\section{MATERIAIS E MÉTODOS}

Trata-se de uma revisão integrativa da literatura. Os dados foram coletados no período de novembro de 2019 a abril de 2020 através do levantamento das produções científicas sobre terapias aplicadas no tratamento das lesões por queimaduras de terceiro grau e de extensão variável. Os artigos foram selecionados por levantamento em revistas indexadas, utilizando as bases de dados: BDENF- (Banco de dados em Enfermagem); LILACS (Literatura Latino-americana e do Caribe em Ciências da Saúde) e SciELO (Scientific Electronic Library Online), utilizando os seguintes Descritores em Ciência da Saúde (DECS): "Terapias" e "Queimaduras" e "Curativos" associados entre si por meio do operador boleano AND.

Para a seleção dos artigos foram definidos os seguintes critérios de inclusão: artigos científicos, gratuitos, no idioma português e inglês, publicados entre 2009 a 2019 na modalidade de texto completo e originais. Como critérios de exclusão: estudos que não apresentaram resultados condizentes com a proposta da revisão.

Para a seleção dos artigos, procedeu-se à leitura minuciosa dos títulos e resumos, atentando para a sua relação com a questão norteadora e aos critérios de inclusão adotados. Na busca inicial com os descritores nas bases de dados LILACS, BDENF e SciELO foram utilizados filtros para publicações disponíveis em texto completo, artigos publicados em português, inglês e filtros do ano de publicação. Por fim, foi realizada a leitura dos títulos e dos resumos que restaram para serem incluídos na revisão integrativa.

\section{RESULTADOS E DISCUSSÃO}

Foram encontrados 73 artigos inicialmente. Destes, 34 foram excluídos por não apresentarem texto completo e dez artigos por terem publicação anterior a 2009. Após essa seleção, foi realizada a leitura dos títulos e resumos, excluindo-se cinco artigos por apresentarem resultados não condizentes com a proposta do estudo. Em seguida, realizou-se a leitura na íntegra dos artigos, excluindo-se sete estudos por não se adequarem ao objetivo, sendo incluídos nesta pesquisa 17 artigos, três no idioma inglês e 14 em português. 


\section{Quadro I}

Descrição dos artigos incluídos na revisão: autores, título, objetivo, método e resultados.

\begin{tabular}{|c|c|c|c|c|}
\hline Autores & Título & Objetivo & Método & Resultados \\
\hline $\begin{array}{l}\text { Montes SF, } \\
\text { Barbosa MH, } \\
\text { Neto ALS }{ }^{9}\end{array}$ & $\begin{array}{l}\text { Aspectos clínicos e } \\
\text { epidemiológicos de } \\
\text { pacientes queimados } \\
\text { internados em um } \\
\text { Hospital de Ensino, } \\
2011 .\end{array}$ & $\begin{array}{l}\text { Caracterizar os pacientes } \\
\text { internados vítimas de } \\
\text { queimaduras e identi- } \\
\text { ficar os tratamentos e } \\
\text { procedimentos invasivos } \\
\text { adotados e as principais } \\
\text { complicações apresenta- } \\
\text { das por estes pacientes. }\end{array}$ & $\begin{array}{l}\text { Estudo } \\
\text { retrospectivo, } \\
\text { descritivo com } \\
\text { abordagem } \\
\text { quantitativa. }\end{array}$ & $\begin{array}{l}\text { Durante o período de janeiro } \\
\text { de } 2003 \text { a dezembro de } 2007 \\
\text { foram atendidos } 346 \text { pacien- } \\
\text { tes vítimas de queimaduras } \\
\text { no HC-UFTM, dos quais } 208 \\
(60,1 \%) \text { foram liberados após } \\
\text { o atendimento na Unidade de } \\
\text { Pronto Socorro e } 138(39,9 \%) \\
\text { foram internados. }\end{array}$ \\
\hline $\begin{array}{l}\text { Teodoro AL, } \\
\text { Paiva VS }{ }^{10}\end{array}$ & $\begin{array}{l}\text { Perfil epidemiológico } \\
\text { de pacientes queima- } \\
\text { dos admitidos em um } \\
\text { serviço terciário de } \\
\text { Caxias do Sul - RS, } \\
2013 .\end{array}$ & $\begin{array}{l}\text { Determinar o perfil epi- } \\
\text { demiológico de pacientes } \\
\text { queimados admitidos em } \\
\text { um serviço terciário de } \\
\text { Caxias do Sul/RS. }\end{array}$ & $\begin{array}{l}\text { Estudo } \\
\text { transversal, } \\
\text { análise de } \\
\text { prontuários. }\end{array}$ & $\begin{array}{l}\text { O grau de lesão misto foi } \\
\text { predominante em } 64,5 \% \\
\text { e em relação à superfície } \\
\text { corporal queimada (SCQ), } \\
\text { prevaleceram pacientes } \\
\text { grandes queimados }(83,9)\end{array}$ \\
\hline $\begin{array}{l}\text { Duarte MLC } \\
\text { et al. }{ }^{11}\end{array}$ & $\begin{array}{l}\text { Percepções da equipe } \\
\text { de enfermagem } \\
\text { sobre o seu trabalho } \\
\text { em uma unidade de } \\
\text { queimados, } 2012 .\end{array}$ & $\begin{array}{l}\text { Analisar a percepção dos } \\
\text { profissionais de enferma- } \\
\text { gem sobre o seu trabalho } \\
\text { em uma Unidade } \\
\text { de Queimados. }\end{array}$ & $\begin{array}{l}\text { Estudo de } \\
\text { abordagem } \\
\text { qualitativa, de } \\
\text { caráter explora- } \\
\text { tório-descritivo. }\end{array}$ & $\begin{array}{l}\text { O preconceito das pessoas } \\
\text { em relação às cicatrizes da } \\
\text { queimadura foram percebi- } \\
\text { dos, pela enfermagem, como } \\
\text { características que dificultam a } \\
\text { reinserção social dos pacientes } \\
\text { queimados, no pós-alta. }\end{array}$ \\
\hline $\begin{array}{l}\text { Freitas MS } \\
\text { et al. }{ }^{12}\end{array}$ & \begin{tabular}{|l|} 
Características \\
epidemiológicas dos \\
pacientes com quei- \\
maduras de terceiro \\
grau no Hospital \\
de Urgências de \\
Sergipe, 2015. \\
\end{tabular} & $\begin{array}{l}\text { Identificar a taxa de pre- } \\
\text { valência e as característi- } \\
\text { cas da população acome- } \\
\text { tida por queimaduras de } \\
\text { terceiro grau no estado } \\
\text { de Sergipe. }\end{array}$ & $\begin{array}{l}\text { Estudo de } \\
\text { abordagem } \\
\text { quantitativa, do } \\
\text { tipo retrospectivo } \\
\text { e descritivo. }\end{array}$ & $\begin{array}{l}\text { Analisados } 182 \text { registros. } \\
\text { Maior prevalência de adultos, } \\
\text { do gênero masculino, com } \\
\text { queimaduras provocadas por } \\
\text { agente térmico. }\end{array}$ \\
\hline $\begin{array}{l}\text { Silva MP, Silva } \\
\text { CCS }^{13}\end{array}$ & $\begin{array}{l}\text { O uso de tecnolo- } \\
\text { gias de curativos em } \\
\text { grandes queimados e } \\
\text { o tempo de } \\
\text { hospitalização, } 2019 .\end{array}$ & $\begin{array}{l}\text { Avaliar o tempo de hos- } \\
\text { pitalização na Unidade de } \\
\text { Terapia de Queimados do } \\
\text { Hospital Tereza Ramos } \\
\text { em Lages/SC. }\end{array}$ & $\begin{array}{l}\text { Estudo } \\
\text { observacional } \\
\text { descritivo e } \\
\text { transversal. }\end{array}$ & $\begin{array}{l}\text { A sulfadiazina de prata a } 1 \% \text { é } \\
\text { o curativo de maior empregabi- } \\
\text { lidade. Já o uso da matriz } \\
\text { dérmica se restringe a situações } \\
\text { com grande perda de funciona- } \\
\text { lidade do local acometido. }\end{array}$ \\
\hline $\begin{array}{l}\text { Moser HH } \\
\text { et al. }{ }^{14}\end{array}$ & $\begin{array}{l}\text { Uso de curativos } \\
\text { impregnados com } \\
\text { prata no trata- } \\
\text { mento de crianças } \\
\text { queimadas inter- } \\
\text { nadas no Hospital } \\
\text { Infantil Joana de } \\
\text { Gusmão,2014. }\end{array}$ & $\begin{array}{l}\text { Analisar os resultados } \\
\text { do uso dos curativos de } \\
\text { prata no tratamento de } \\
\text { queimaduras em crianças } \\
\text { atendidas no Hospital } \\
\text { Infantil Joana de Gusmão } \\
\text { (HIJG). }\end{array}$ & $\begin{array}{l}\text { Estudo retros- } \\
\text { pectivo de } \\
\text { delineamento } \\
\text { transversal. }\end{array}$ & $\begin{array}{l}\text { A sulfadiazina de prata foi o } \\
\text { tipo de curativo mais utilizado, } \\
\text { seguido pela prata nanocris- } \\
\text { talina. O tempo decorrido até } \\
\text { a reepitelização completa da } \\
\text { queimadura foi menor que } 21 \\
\text { dias para a maioria da } \\
\text { população estudada. }\end{array}$ \\
\hline $\begin{array}{l}\text { Costa Filho } \\
\text { MAR et al. }{ }^{15}\end{array}$ & $\begin{array}{l}\text { Tratamento } \\
\text { ambulatorial de } \\
\text { queimaduras com } \\
\text { prata nanocristalina } \\
\text { em malha flexível: } \\
\text { uma alternativa } \\
\text { terapêutica, } 2012 \text {. }\end{array}$ & $\begin{array}{l}\text { Avaliar a eficácia e o } \\
\text { tempo de tratamento de } \\
\text { pacientes em tratamento } \\
\text { ambulatorial com prata } \\
\text { nanocristalina em malha } \\
\text { flexível na Unidade de } \\
\text { Tratamento de Queimados } \\
\text { do Hospital Regional de } \\
\text { Sorocaba. }\end{array}$ & Série de casos. & $\begin{array}{l}\text { A média de dias dos curativos } \\
\text { contendo a malha de poliéster } \\
\text { com prata nanocristalina foi } \\
\text { de } 13 \text { dias e mostrou-se eficaz } \\
\text { na cicatrização de } \\
\text { queimaduras e uma } \\
\text { boa alternativa terapêutica. }\end{array}$ \\
\hline $\begin{array}{l}\text { Moreira SS } \\
\text { et al. }{ }^{16}\end{array}$ & $\begin{array}{l}\text { Implantação de nova } \\
\text { tecnologia para } \\
\text { otimização do } \\
\text { atendimento em } \\
\text { ambulatório de } \\
\text { queimados, sem } \\
\text { adição de custos, } \\
2013 \text {. }\end{array}$ & $\begin{array}{l}\text { Analisar o custo, efetivida- } \\
\text { de e segurança dos } \\
\text { curativos de prata nano- } \\
\text { cristalina e da sulfadiazina } \\
\text { de prata } 1 \% \text { no trata- } \\
\text { mento ambulatorial de } \\
\text { pacientes queimados. }\end{array}$ & $\begin{array}{l}\text { Estudo } \\
\text { observacional } \\
\text { analítico. }\end{array}$ & $\begin{array}{l}\text { Comparando os custos nos } \\
\text { sete casos analisados, obser- } \\
\text { vamos que houve economia de } \\
15 \% \text { quando utilizado o curati- } \\
\text { vo de prata nanocristalina em } \\
\text { comparação com o curativo } \\
\text { tradicional utilizando creme de } \\
\text { sulfadiazina de prata } 1 \% \text {. }\end{array}$ \\
\hline
\end{tabular}


Quadro I (Continuação)

\begin{tabular}{|c|c|c|c|c|}
\hline Autores & Título & Objetivo & Método & Resultados \\
\hline $\begin{array}{l}\text { Farina-Junior } \\
\text { JA et al. }{ }^{17}\end{array}$ & $\begin{array}{l}\text { Curativos de prata } \\
\text { iônica como substi- } \\
\text { tutos da sulfadiazina } \\
\text { para feridas de quei- } \\
\text { maduras profundas: } \\
\text { relato de caso, } 2017 .\end{array}$ & $\begin{array}{l}\text { Relatar as possíveis van- } \\
\text { tagens de curativos na } \\
\text { forma de lâminas impreg- } \\
\text { nadas com prata iônica } \\
\text { como agentes tópicos } \\
\text { substitutos do creme } \\
\text { de sulfadiazina de prata } \\
1 \% \text { nas queimaduras } \\
\text { profundas. }\end{array}$ & Relato de Caso. & $\begin{array}{l}\text { Os curativos na forma de lâmi- } \\
\text { nas impregnadas oferecem } \\
\text { uma enorme vantagem de as } \\
\text { trocas serem espaçadas entre } \\
4 \text { a } 7 \text { dias, quando compara- } \\
\text { dos à sulfadiazina, que exige } \\
\text { a troca diária dos curativos, } \\
\text { minimizando dor e desconforto } \\
\text { aos pacientes. }\end{array}$ \\
\hline $\begin{array}{l}\text { Ranjbar R, } \\
\text { Takhtfooladi } \\
\text { MA }^{18}\end{array}$ & $\begin{array}{l}\text { The effects of low } \\
\text { level laser therapy } \\
\text { on Staphylococcus } \\
\text { aureus infected } \\
\text { third-degree } \\
\text { burns in diabetic } \\
\text { rats, } 2016 .\end{array}$ & $\begin{array}{l}\text { To characterize the effects } \\
\text { of low-level laser (LLL) on } \\
\text { third-degree burn wounds } \\
\text { which were infected with } \\
\text { Staphylococcus } \\
\text { aureus (S. aureus) in } \\
\text { diabetic rats. }\end{array}$ & Clinical trial & $\begin{array}{l}\text { The low-level laser } \\
\text { improved the healing of } \\
\text { S. aureus third-degree burn } \\
\text { infections in diabetic rats. }\end{array}$ \\
\hline $\begin{array}{l}\text { Gomes MT } \\
\text { et al. }{ }^{19}\end{array}$ & $\begin{array}{l}\text { Experimental burns: } \\
\text { Comparison between } \\
\text { silver sulfadiazine } \\
\text { and photobiomodula- } \\
\text { tion, } 2017 .\end{array}$ & $\begin{array}{l}\text { To analyze morphological } \\
\text { characteristics and organi- } \\
\text { zation of the } \\
\text { collagen fibers of third } \\
\text { degree burns from scal- } \\
\text { ding compared to laser } \\
\text { therapy } \\
\text { and silver sulfadiazine, } \\
\text { the latter considered as } \\
\text { the gold standard. }\end{array}$ & Clinical trial. & $\begin{array}{l}\text { Morphologically, the laser or } \\
\text { silver sulfadiazine treatments } \\
\text { were similar and both provided } \\
\text { better organization of collagen } \\
\text { fibers in relation to the untrea- } \\
\text { ted group. }\end{array}$ \\
\hline $\begin{array}{l}\text { Campos DLP } \\
\text { et al. }{ }^{20}\end{array}$ & $\begin{array}{l}\text { Uso de curativo com } \\
\text { prata nanocristalina } \\
\text { sobre enxerto em } \\
\text { malha em queima- } \\
\text { duras colonizadas } \\
\text { por cepas multirre- } \\
\text { sistentes, } 2009 \text {. }\end{array}$ & $\begin{array}{l}\text { Descrever a eficiência do } \\
\text { curativo com prata nano- } \\
\text { cristalina sobre enxerto } \\
\text { em malha em queimadu- } \\
\text { ras com colonização por } \\
\text { cepas multirresistentes. }\end{array}$ & Estudo de caso. & $\begin{array}{l}\text { O estudo mostrou um resulta- } \\
\text { do positivo, todos os pacientes } \\
\text { apresentaram melhora na } \\
\text { integração do enxerto. }\end{array}$ \\
\hline $\begin{array}{l}\text { Oliveira AF, } \\
\text { Ferreira } \text { LM }^{21}\end{array}$ & $\begin{array}{l}\text { Procedures in the } \\
\text { care of hand burns } \\
\text { in the acute phase, } \\
2017 .\end{array}$ & $\begin{array}{l}\text { Describe the routine } \\
\text { treatment of patients with } \\
\text { burns involving one or } \\
\text { both hands. }\end{array}$ & $\begin{array}{l}\text { Descriptive } \\
\text { research. }\end{array}$ & $\begin{array}{l}\text { Half of the patients enrolled } \\
\text { in the study needed opera- } \\
\text { tive treatment for the hands } \\
(50.8 \%) \text {, and in this group, } \\
\text { the lesions were partial deep } \\
\text { thickness or total thickness. } \\
\text { No graft loss was identified in } \\
\text { the operated group. }\end{array}$ \\
\hline $\begin{array}{l}\text { Guerra ACPCS } \\
\text { et al. } .^{22}\end{array}$ & $\begin{array}{l}\text { Queimadura com } \\
\text { exposição óssea dos } \\
\text { membros inferio- } \\
\text { res: reconstrução } \\
\text { com matriz de } \\
\text { regeneração } \\
\text { dérmica, } 2011 \text {. }\end{array}$ & $\begin{array}{l}\text { Apresentar } 2 \text { casos de } \\
\text { queimaduras graves } \\
\text { com exposição óssea } \\
\text { dos membros inferiores, } \\
\text { salientando a eficácia da } \\
\text { matriz de regeneração } \\
\text { dérmica. }\end{array}$ & $\begin{array}{l}\text { Estudo retrospec- } \\
\text { tivo e relato de } \\
\text { caso. }\end{array}$ & $\begin{array}{l}\text { Permite uma cobertura está- } \\
\text { vel, com } \\
\text { morbidade mínima de zona } \\
\text { doadora e assegura resultado } \\
\text { estético satisfatório. }\end{array}$ \\
\hline $\begin{array}{l}\text { Aldunate JLCB } \\
\text { et al. } .^{23}\end{array}$ & $\begin{array}{l}\text { Uso de matriz dér- } \\
\text { mica associado ao } \\
\text { curativo por pressão } \\
\text { negativa na aborda- } \\
\text { gem da contratura } \\
\text { em pacientes } \\
\text { queimados, } 2012 \text {. }\end{array}$ & $\begin{array}{l}\text { Demonstrar o uso da } \\
\text { matriz dérmica artificial } \\
\text { associado } \\
\text { a terapia por pressão } \\
\text { negativa no tratamento de } \\
\text { sequelas de queimaduras. }\end{array}$ & Série de casos. & $\begin{array}{l}\text { O uso da matriz de regene- } \\
\text { ração dérmica associado a } \\
\text { terapia por pressão } \\
\text { negativa promove maior taxa } \\
\text { de sucesso na abordagem da } \\
\text { contratura cicatricial. }\end{array}$ \\
\hline
\end{tabular}


Quadro I (Continuação)

\begin{tabular}{|l|l|l|l|l|}
\hline \multicolumn{1}{|c|}{ Autores } & \multicolumn{1}{|c|}{ Título } & \multicolumn{1}{c|}{ Objetivo } & \multicolumn{1}{c|}{ Método } & \multicolumn{1}{c|}{ Resultados } \\
\hline $\begin{array}{l}\text { Miranda MJB, } \\
\text { Brandt CT }{ }^{24}\end{array}$ & $\begin{array}{l}\text { Xenoenxerto (pele } \\
\text { da Tilápia-do-Nilo) e } \\
\text { hidrofibra } \\
\text { com prata no trata- } \\
\text { mento das queima- } \\
\text { duras de II grau } \\
\text { em adultos, 2019. }\end{array}$ & $\begin{array}{l}\text { Avaliar a eficácia da utili- } \\
\text { zação da } \\
\text { pele da Tilápia como cura- } \\
\text { tivo biológico oclusivo, no } \\
\text { manejo/ tratamento de } \\
\text { queimaduras de } \\
2^{\circ} \text { grau em adultos. }\end{array}$ & $\begin{array}{l}\text { Estudo clínico. } \\
\text { ca pele da Tilápia-do-Nilo é efi- } \\
\text { queimaduras de 20 grau em } \\
\text { adultos, comparativamente ao } \\
\text { curativo à base } \\
\text { de hidrofibra com prata. }\end{array}$ \\
\hline $\begin{array}{l}\text { Lima-Junior } \\
\text { EM et al.25 }\end{array}$ & $\begin{array}{l}\text { Uso da pele de tilápia } \\
\text { (Oreochromis niloti- } \\
\text { cus), como curativo } \\
\text { biológico oclusivo, no } \\
\text { tratamento de quei- } \\
\text { maduras, 2017. }\end{array}$ & $\begin{array}{l}\text { Avaliar a utilização da pele } \\
\text { de tilápia do Nilo como } \\
\text { curativo oclusivo tempo- } \\
\text { rário nas queimaduras de } \\
\text { segundo grau superficial e } \\
\text { profunda em ratos. }\end{array}$ & $\begin{array}{l}\text { Estudo } \\
\text { prospectivo, } \\
\text { qualiquantitativo. }\end{array}$ & $\begin{array}{l}\text { Um melhor delineamento dos } \\
\text { bordos da ferida no processo } \\
\text { de cicatrização, nos grupos em } \\
\text { tratamento com a pele } \\
\text { da tilápia. }\end{array}$ \\
\hline
\end{tabular}

Fonte: Dados dos autores.

A fim de facilitar o entendimento do leitor optou-se em agrupar os resultados e realizar as discussões em duas categorias, sendo elas: caracterização dos aspectos clínicos das queimaduras de grande porte e terapias utilizadas no tratamento das lesões por queimaduras extensas e de terceiro grau.

\section{Caracterização dos aspectos clínicos das queimaduras de grande porte}

Do ponto de vista clínico, as queimaduras são lesões de grande complexidade, de tratamento difícil, que requerem uma equipe multidisciplinar, com elevada taxa de morbimortalidade em todo mundo, acometendo milhões de pessoas por ano. A resposta do organismo do paciente vai depender do agente etiológico, grau de comprometimento da lesão e a extensão da queimadura. Quanto à profundidade, podem comprometer desde a epiderme, causando eritema e dor ou até todas as camadas da pele e estruturas mais profundas. Nas queimaduras de terceiro grau a coloração varia desde branco pálido, vermelho, marrom ou negro carbonizado; a área queimada é indolor, porque os filetes nervosos são destruídos, tornando as lesões de maior gravidade. A ruptura da pele pode levar a perda de líquidos, infecções, hipotermia, comprometimento da imunidade, alterações na função e imagem corporal ${ }^{9}$.

Considerando a importância do tratamento ao paciente queimado, uma maneira utilizada para se classificar um ferimento por queimadura é por meio da extensão da superfície corporal queimada (SCQ), na qual se dividem os pacientes em pequeno, médio ou grande queimado. Para os casos considerados pequenos queimados, estão as crianças com SCQ inferior a $10 \%$ e os adultos com SCQ de $15 \%$. Já o médio queimado é caracterizado por uma SCQ entre $10 \%$ e $20 \%$ e o grande queimado por uma SCQ maior que $10 \%$ nas crianças e $20 \%$ nos adultos ${ }^{10}$.

Mediante essa classificação, outros autores corroboram que, no geral, as infecções acontecem em pacientes que tenham mais de $30 \%$ da superfície corporal total queimada. Diante disso, a equipe de saúde deve observar sinais de infecção no local da queimadura, esses sinais incluem: coloração escurecida da área queimada, progressão de uma necrose parcial para uma necrose total, tecido subcutâneo com coloração esverdeada, surgimento de vesículas em lesões cicatrizadas e de sinais flogísticos em áreas próximas às queimaduras. Deve-se atentar a qualquer alteração na aparência da lesão, pois pode ser indicativo de infecção, visto que representa a mais frequente e grave complicação no paciente queimado ${ }^{11}$.

Quando o tratamento do paciente queimado necessitar de um curativo, a escolha do material para sua realização decorre do conhecimento tanto fisiopatológico como bioquímico dos mecanismos de cicatrização e reparação tissular, considerando que as lesões por queimaduras de terceiro grau não reepitelizam e muitas vezes necessitam de enxertia de pele ${ }^{12}$. 
Terapias utilizadas no tratamento das lesões por queimaduras extensas e de terceiro grau

Dentre os estudos analisados foi verificado que a prata é o medicamento chave no tratamento de queimaduras usado ao longo dos anos, apresentando como vantagem o controle de infecções e como desvantagem a necessidade de trocas constantes, o que ocasiona dor e elevado custo. Outros estudos abordam variados produtos à base de prata, e entre eles se sobressaem a sulfadiazina de prata $1 \%$, a prata nanocristalina e o alginato de prata. A sulfadiazina de prata a $1 \%$ constitui método inicial de todas as lesões por queimadura. Em coadjuvância, destaca-se o uso do hidrogel, que mantem as lesões úmidas e isoladas do meio externo ${ }^{13}$.

A sulfadiazina de prata possui um efeito antimicrobiano bastante amplo, pela sua ação bactericida variada, e age em uma grande variedade de bactérias Gram-positivas e Gram-negativas, além de ser eficaz em algumas espécies de fungos. Sua ação antimicrobiana é devido a reação do íon de prata com o DNA microbiano, o que bloqueia a replicação bacteriana ${ }^{14}$.

Como citado anteriormente, a prata nanocristalina também é usada neste tipo de tratamento, e dentre os estudos analisados, este tipo de curativo foi citado por alguns autores, tendo por objetivo ser barreira antimicrobiana e permitir mínimas concentrações inibitórias com capacidade rápida bactericida maior que os curativos a base de sulfadiazina e nitrato de prata. Além disso, tem como vantagem a necessidade de menos trocas, permitindo uma liberação prolongada e sustentada de prata no leito da lesão. Quanto ao seu elevado custo, um estudo revelou economia de $15 \%$ quando utilizado o curativo de prata nanocristalina em comparação com o curativo tradicional utilizando creme de sulfadiazina de prata $1 \%$, levando-se em consideração a média de curativos realizados ${ }^{16}$.

E se tratando de novas terapias, os curativos com prata vêm acompanhando esta tendência, como exemplo cita-se os curativos de espuma absorvente que englobam a prata com analgésicos e anti-inflamatórios, estes curativos liberam suas substâncias de forma contínua, à proporção que o exsudato é absorvido. Essa nova terapia destaca-se por apresentar uma maior velocidade de restauração tecidual, diminuindo as dores e a ocorrência de infecções, pois evitam o acúmulo de exsudato, além disso, possibilita ao paciente realizar a própria troca do curativo, sem a necessidade de voltar frequentemente à unidade de saúde ${ }^{17}$.

Em ensaio clínico com ratos, foi evidenciado que a terapia a LASER de baixa intensidade induziu a destruição de de $S$. Aureus nas queimaduras de terceiro grau, reduziu reação inflamatória e proporcionou melhor deposição do colágeno, amenizando a cicatrização deste tipo de lesão . Outro estudo, também realizado com ratos, demonstrou que o grupo tratado com terapia a LASER apresentou resposta inflamatória mais amena, enquanto o grupo em que foi utilizado sulfadiazina de prata a $1 \%$ modulou a deposição das fibras de colágeno com mais eficiência, evidenciando um melhor processo cicatricial em relação ao grupo tratado com LASER e o grupo controle ${ }^{19}$.

O desafio atual no tratamento de queimaduras é a substituição eficaz da pele, o enxerto em malha ou enxerto da pele de espessura dividida (STGS), autoenxerto, onde parte da pele não lesionada do próprio paciente é utilizada como área doadora. Em se tratando de queimaduras envolvendo as mãos, atenção e cuidados locais adequados são necessários, pois a enxertia de pele precoce é fundamental na prevenção de sequelas funcionais graves ${ }^{21}$.

Contudo, nem todos os doentes são candidatos à transferência de tecidos vascularizados: doentes instáveis, com alterações hemodinâmicas ou doentes com lesões amplas de tecidos que inviabilizam a mobilização de tecidos localmente. Neste contexto, e para casos particulares mais complexos, a matriz de regeneração dérmica assume-se como uma alternativa eficaz e segura. A aplicação deste substituto dérmico exige a garantia de um leito receptor limpo, desprovido de tecido necrótico ou desvitalizado e impõe a ocorrência de um segundo tempo operatório para a substituição da película de silicone por enxerto de pele e um acompanhamento dos curativos por equipe qualificada ${ }^{22}$.

Em muitos casos, a contratura cicatricial comum em grandes queimados promove sequelas limitantes e desfigurantes aos pacientes. Essas contraturas podem causar grave comprometimento funcional, limitações às atividades cotidianas e afastamento do convívio social. Além disso, em 
crianças podem ocorrer deformidades do esqueleto, gerando sequelas permanentes e irreversíveis. A utilização da terapia por pressão negativa no tratamento da contratura cicatricial, além de proporcionar maior taxa de sucesso, agrega como vantagem o fato de o paciente não precisar ficar imobilizado e imóvel após as cirurgias, pelo receio de deslocar a matriz ou o enxerto do leito receptor, já que a pressão negativa promove estabilidade das estruturas abaixo desse curativo ${ }^{23}$.

Estamos distantes de um substituto cutâneo temporário ideal, mas o uso de curativos biológicos constitui uma alternativa de tratamento com melhores resultados funcionais e estéticos. Neste sentido, a pele da Tilápia-do-Nilo é apontada como um produto promissor ${ }^{24}$. Os ferimentos provocados por queimaduras tratados com a pele de tilápia apresentam um padrão de cicatrização superior, isso é devido a sua capacidade de ocluir a lesão, diminuir exsudatos e a formação de crostas. Salienta-se, que apesar dos benefícios evidenciados no uso da pele de tilápia como terapia em lesões causadas por queimaduras, existem poucos estudos publicados sobre esta aplicação, o que restringe seu uso.

\section{CONSIDERAÇÕES FINAIS}

Percebeu-se com este estudo que, com o passar dos anos, inovações terapêuticas vêm sendo estudadas para serem implantadas no tratamento ao paciente queimado. Foi apontado em muitos estudos a utilização dos curativos a base de prata, usada mundialmente por seu alto poder antimicrobiano eficaz contra as infecções, no entanto, a substituição de pele vem ganhando espaço pelos resultados positivos, como evidenciado no tratamento com pele de tilápia, o que aponta para um futuro promissor, além do que constitui técnica genuinamente brasileira, simples e barata.

A indicação e a aplicação de terapias em queimaduras devem ser realizadas com base na avaliação criteriosa da ferida, das condições clínicas do paciente, bem como na análise das evidências na literatura, afinal o tratamento convencional de grandes queimados é complexo e oneroso para o sistema de saúde. Desse modo é preciso sistematizar os cuidados e procedimentos quanto às novas terapias disponíveis para o tratamento de queimaduras, como formas de amenizar os agravos e sintomatologias, melhorando o prognóstico do paciente.

\section{REFERÊNCIAS}

1. Lafaiete, C. Queimaduras: um problema atemporal e persistente. Portal PEBMED, 2019. Disponível em: https://pebmed.com.br/queimaduras-um-problemaatemporal-e-persistente/. Acesso em: 20 dez. 2019.

2. Brasil. Ministério da Saúde. Queimados, 2017. Disponível em: http://www.saude.gov.br/component/ content/article/842-queimados/40990. Acesso em: 20 dez. 2019.

3. Morais IH, Daga $H$, Prestes MA. Crianças queimadas atendidas no Hospital Universitário Evangélico de Curitiba: perfil epidemiológico. Rev Bras Queimaduras. 2016; 15(4):256-260.

4. Rodrigues Júnior JL, Bastos NNA, Coelho PAS. Terapia ocupacional em queimados: pesquisa bibliográfica acerca da reabilitação física junto a indivíduos com queimaduras. Rev Bras Queimaduras. 2014;13(1):11-17.

5. Moser H, Pereima RR, Pereima MJL. Evolução dos curativos de prata no tratamento de queimaduras de espessura parcial. Rev Bras Queimaduras. 2013;12(2):60-67.

6. Trancoso KS, Reis CL, Lima JLT. A efetividade do uso de curativos a base de prata em queimaduras: uma overview. In: $2^{\circ}$ International Nursing Congress, Good practices of nursing representations in the construction of society; 09-12 mai 2017; Aracaju. Sergipe(SE): Universidade Tiradentes (UNIT); 2017.

7. Felix DLS, Machado AKP, Silva ESC, Mendonça AEO, Dantas DV, Dantas RAN, et al. Cuidados de enfermagem a pacientes vítimas de ferimentos por queimaduras: revisão de literatura. Rev Feridas. 2015;2(12):448-452.

8. Hernández $C M C$, Núñes $V P$, Suárez FAP, Banqueris RF, Gil SRL, Machado AAB. Mortalidade por queimaduras em pacientes hospitalizados em Manzanillo-Cuba em 2015-2017. Rev Bras Queimaduras. 2018;17(2):8-13.

9. Montes SF, Barbosa MH, Neto ALS. Aspectos clínicos e epidemiológicos de pacientes queimados internados em um hospital de ensino. Rev Esc Enferm USP. 2011;45(2): 369-373.

10. Teodoro AL, Paiva VS. Perfil epidemiológico de pacientes queimados admitidos em um serviço terciário de Caxias do Sul-RS. Rev Bras Queimaduras. 2013;12(2):108-111.

11. Duarte MLC, Lemos L, Zanini LN, Wagnes ZI. Percepções da equipe de enfermagem sobre o seu trabalho em uma unidade de queimados. Rev Gaúcha Enferm. 2012;33(1):77-84.

12. Freitas MS, Machado MM, Moraes RZC, Sousa AH, Aragão LHFB, Santos Junior RA, et al. Características epidemiológicas dos pacientes com queimaduras de 
terceiro grau no Hospital de Urgência de Sergipe. Rev Bras Queimaduras. 2015;14(1):18-22.

13. Silva MP, Silva CCS. O uso de tecnologias de curativos em grandes queimados e o tempo de hospitalização. Rev Gepesvida. 2019;5(11):30-38.

14. Moser HH, Pereima MJL, Soares FF, Feijó R. Uso de curativos impregnados com prata no tratamento de crianças queimadas internadas no Hospital Infantil Joana de Gusmão. Rev Bras Queimaduras. 2014;13(3):147-153.

15. Costa Filho MAR, Ferreira RB, Nunes BB, Bortolucci GAP, Proto RS, Gozanno RN, et al. Tratamento ambulatorial de queimaduras com prata nanocristalina em malha flexível: uma alternativa terapêutica. Rev Bras Qvermaduras. 2012;11(4):226-229.

16. Moreira SS, Macedo AC, Nunes BB, Brasileiro FF, Guarizzo J, Gozanno R, et al. Implantação de nova tecnologia para otimização do atendimento em ambulatório de queimados, sem adição de custos. Rev Bras Queimaduras. 2013;12(2):87-102.

17. Farina-Junior JA, Coltro PS, Oliveira TS, Correa FB, Castro JCD. Curativos de prata iônica como substitutos da sulfadiazina para feridas de queimaduras profundas: relato de caso. Rev Bras Queimaduras. 2017;16(1):53-57.

18. Ranjbar R, Takhtfooladi MA. The effects of low level laser therapy on Staphylococcus aureus infected third-degree burns in diabetic rats. Acta Cir Bras. 2016; 31(4):251-255.

19. Gomes MT, Campos GRS, Piccolo N, França CM, Guedes $\mathrm{GH}$, Lopes F, et al. Experimental burns: Comparison between silver sulfadiazine and photobiomodulation. Rev Assoc Med Bras. 2017;63(1):29-34.

20. Campos DLP, Fragadolli LV, Gimenes GA, Ruiz RO, Orgaes FS, Gonella HA. Uso de curativo com prata nanocristalina sobre enxerto em malha em queimaduras colonizadas por cepas multirresistentes. Rev Bras Cir Plást. 2009;24(3):471-478.

21. Oliveira AF, Ferreira LM. Procedures in the care of hand burns in the acute phase. Rev Bras Cir Plást. 2017;32(2):245-251.

22. Guerra ACPCS, Antunes MPS, Ferreira JPA, Reis GMD. Queimadura com exposição óssea dos membros inferiores: reconstrução com matriz de regeneração dérmica. Rev Bras Cir Plást. 2011;26(1):174-180.

23. Aldunate JLCB, Vana LPM, Fontana C, Ferreira MC. Uso de matriz dérmica associado ao curativo por pressão negativa na abordagem da contratura em pacientes queimados. Rev Bras Cir Plást. 2012;27(3):369-373.

24. Miranda MJB, Brandt CT. Xenoenxerto (pele da Tilápiado-Nilo) e hidrofibra com prata no tratamento das queimaduras de II grau em adultos. Rev Bras Cir Plást. 2019;34(1):79-85.

25. Lima-Junior EM, Picollo NS, Miranda MJB, Ribeiro WLC, Alves APNN, Ferreira GE, et al. Uso da pele de tilápia (Oreochromis niloticus), como curativo biológico oclusivo, no tratamento de queimaduras. Rev Bras Queimaduras. 2017;16(1):10-17. 